\title{
Influence of laminated orientation on the mechanical and thermal characteristics of carbon-fiber reinforced plastics
}

\author{
Hee-Jae Shin ${ }^{1}$, Lee-Ku Kwac ${ }^{2}$, Min-Sang Lee ${ }^{1}$ and Hong-Gun Kim, \\ ${ }^{1}$ Department of Mechanical Engineering, Jeonju University, Jeonju 55069, Korea \\ ${ }^{2}$ Department of Carbon and Nano Engineering, Jeonju University, Jeonju 55069, Korea \\ ${ }^{3}$ Department of Mechanical and Automotive Engineering, Jeonju University, Jeonju 55069, Korea
}

\section{Article Info}

Received 4 May 2015

Accepted 22 June 2015

*Corresponding Author

E-mail: hkim@jj.ac.kr

Tel: $+82-63-220-2613$

\section{Open Access}

DOI: http://dx.doi.org/

10.5714/CL.2015.16.4.241

This is an Open Access article distributed under the terms of the Creative Commons Attribution Non-Commercial License (http://creativecommons.org/licenses/ by-nc/3.0/) which permits unrestricted non-commercial use, distribution, and reproduction in any medium, provided the original work is properly cited.

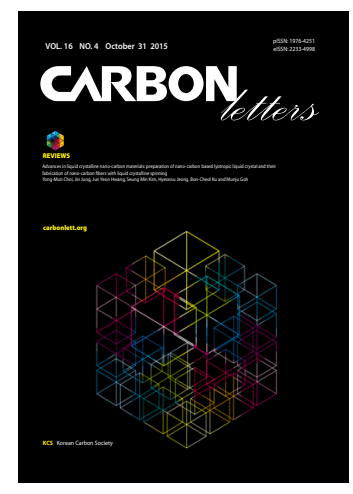

http://carbonlett.org

pISSN: $1976-4251$

elSSN: 2233-4998

Copyright $\odot$ Korean Carbon Society

\begin{abstract}
Rapid industrial development in recent times has increased the demand for light-weight materials with high strength and structural integrity. In this context, carbon fiber-reinforced plastic (CFRP) composite materials are being extensively used. However, laminated CFRPs develop faults during impact because CFRPs are composed of mixed carbon fiber and epoxy. Moreover, their fracturing behavior is very complicated and difficult to interpret. In this paper, the effect of the direction of lamination in CFRP on the absorbed impact energy and impact strength were evaluated, including symmetric ply $\left(0^{\circ} / 0^{\circ},-15^{\circ} /+15^{\circ},-30^{\circ} /+30^{\circ}\right.$, $-45^{\circ} / 45^{\circ}$, and $\left.-90^{\circ} / 90^{\circ}\right)$ and asymmetric ply $\left(0^{\circ} / 15^{\circ}, 0^{\circ} / 30^{\circ}, 0^{\circ} / 45^{\circ}\right.$, and $\left.0^{\circ} / 90^{\circ}\right)$, through drop-weight impact tests. Further, the thermal properties of the specimens were measured using an infrared camera. Correlations between the absorbed impact energy, impact strength, and thermal properties as determined by the drop-weight impact tests were analyzed. These analyses revealed that the absorbed impact energy of the specimens with asymmetric laminated angles was greater than that of the specimens with symmetric laminated angles. In addition, the asymmetry ply absorbed more impact energy than the symmetric ply. Finally, the absorbed impact energy was inversely proportional to the thermal characteristics of the specimens.
\end{abstract}

Key words: carbon fiber reinforced plastic, drop-weight impact test, infrared camera, absorbed impact energy, impact strength

\section{Introduction}

Among the various advanced composite materials used for aerospace structures, such as those in aircrafts and space devices, carbon fiber-reinforced plastics (CFRP) are applied in many sectors that require lightweight materials for high strength and stiffness, including the aerospace industry. These materials are used as rotating casings for centrifuges, compressor rotor blades for aircraft, and rotor blades for helicopters. However, one of the disadvantages of CFRPs is that they are weak against impact.

The residual compressive strengths of graphite/epoxy and graphite/polyether ether ketone (PEEK) have been evaluated during foreign object damage (FOD) of CFRP, using laminated material structures which have residual tensile strength after impact. Further, low-speed impact damage evaluations [1] have been performed on laminated composite materials using curvature and piezoelectric film sensors [2] to evaluate the starting point of the impact damage of the composite material. Most of the test methods available are impact strength evaluation methods for composite materials or metals, employing Charpy and I-zod impact tests with drop-weights and Dynatup.

Precise measurements and evaluations of the impacts are particularly essential for composite materials with anisotropy, and the causes of decreased strength due to impact damage 
have not been fully explained yet. Therefore, the fracture mechanism must be further studied to explain the decreased strength due to impact damage [3]

In addition, composite materials are being increasingly used in many sectors because their design parameters can be modified according to the requirements of the target structures. The design parameters for composite materials include laminating direction, order, and thickness. Understanding characteristics such as stiffness and strength is very important for choosing the appropriate design parameters [3].

In this study, drop-weight tests were conducted while varying the symmetric and asymmetric fiber-laminated angles to examine the impact strength and absorbed energy as a function of the fiber-laminated angle. The CFRP was laminated with various laminated angles and formed using the vacuum bag method. The tests were conducted according to the standards prescribed in American Society for Testing Materials (ASTM)-D7136.

\section{Experimental}

The composite material used in this study was USN150B $(0.146 \mathrm{~mm}$ thick $)$, which is a unidirectional carbon fiber prepreg obtained from SK Chemicals (Seongnam, Korea). This prepreg was laminated in 32 plies and was formed at $125^{\circ} \mathrm{C}$ and 0.1 bar in the vacuum state for approximately $90 \mathrm{~min}$. Table 1 shows the chemical and mechanical properties of the material, while Table 2 shows the test conditions. The thermal characteristics of the material were analyzed by measuring the thermal image temperature distribution using an infrared thermal camera. Fig. 1 shows a schematic image of the impact test specimens, whereas Fig. 2 [4] shows the ex-

Table 1. Chemical composition of the unidirectional prepreg composite

\begin{tabular}{cc} 
Variable & Value \\
\hline Thickness $(\mathrm{mm})$ & 0.146 \\
Fiber areal weight $\left(\mathrm{g} / \mathrm{m}^{2}\right)$ & 150 \\
Resin content $(\%)$ & 33 \\
Total weight $\left(\mathrm{g} / \mathrm{m}^{2}\right)$ & 224 \\
Tensile strength $\left(\mathrm{kg}_{\mathrm{f}} / \mathrm{mm}^{2}\right)$ & 450 \\
Tensile modulus $\left(\mathrm{kg} / \mathrm{mm}^{2}\right)$ & $24 \times 103$ \\
Fiber density $\left(\mathrm{g} / \mathrm{cm}^{3}\right)$ & 1.77 \\
Resin density $\left(\mathrm{g} / \mathrm{cm}^{3}\right)$ & 1.2 \\
\hline
\end{tabular}

Table 2. Experimental conditions for the drop-weight impact tests

\begin{tabular}{cccc}
$\begin{array}{c}\text { Impact + velocity } \\
(\mathrm{m} / \mathrm{s})\end{array}$ & $\begin{array}{c}\text { Drop weight } \\
(\mathrm{kg})\end{array}$ & $\begin{array}{c}\text { Test energy } \\
(\mathrm{J})\end{array}$ & $\begin{array}{c}\text { Test height } \\
(\mathrm{m})\end{array}$ \\
\hline 3.3391 & 5.5000 & 31.0000 & 0.5761 \\
\hline
\end{tabular}

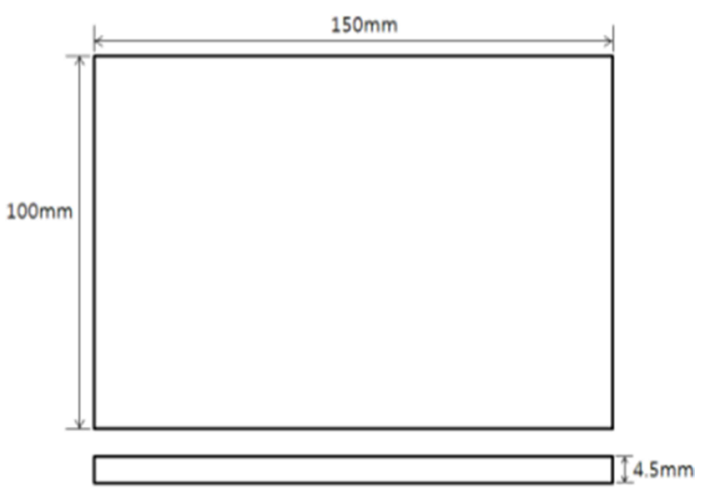

Fig. 1. Schematic illustration of the impact test specimens.

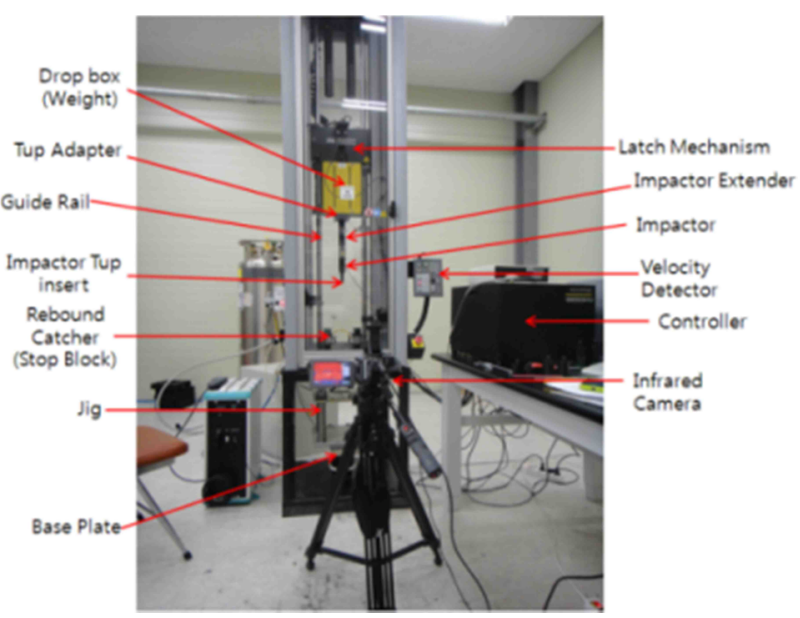

Fig. 2. Experimental system for the drop-weight impact tests.

perimental setup for the drop-weight tests with an infrared thermography camera [5].

The impact test specimens were manufactured with symmetry ply $\left(0^{\circ} / 0^{\circ},-15^{\circ} / 15^{\circ},-30^{\circ} /+30^{\circ},-45^{\circ} /+45^{\circ}\right.$, and $\left.-90^{\circ} /+90^{\circ}\right)$ as well as asymmetry ply $\left(0^{\circ} / 15^{\circ}, 0^{\circ} / 30^{\circ}, 0^{\circ} / 45^{\circ}\right.$, and $0^{\circ} / 90^{\circ}$ ) according to ASTM D7136, and then dropweight tests were performed. Since ensuring an accurate impact position and good reproducibility are important for the drop-weight impact test device, it must have a vertical guide rail. Dynatup $9250 \mathrm{HV}$ from Manufacturer I provides up to $1182 \mathrm{ft}-\mathrm{lbs}(1603 \mathrm{~J})$ of impact energy, up to $65.6 \mathrm{ft} / \mathrm{s}(20$ $\mathrm{m} / \mathrm{s}$ ) impact speed, and a maximum drop height of $20.4 \mathrm{~m}$. Its data acquisition speed is $5 \mathrm{MHz} / \mathrm{s}$. The test conditions were set considering the specimen thickness and size, according to ASTM D7136 [6,7].

\section{Results and Discussion}

The drop-weight impact tests were conducted with three specimens for each fiber-laminated angle. The strain and load were measured as a function of the laminated angle. The absorbed energy is represented by the area under the curve in the load-displacement graph. Fig. 3 show the results of the 


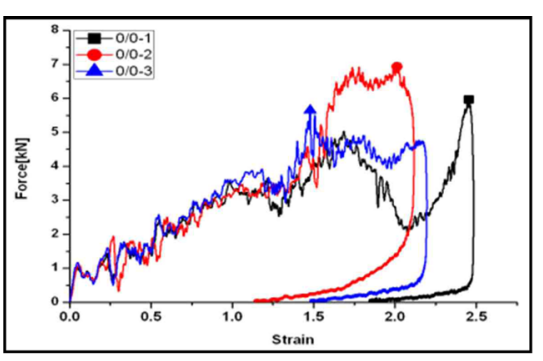

(a) $0^{\circ} / 0^{\circ}$

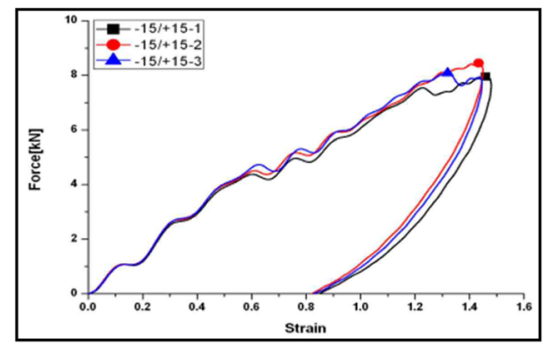

(b) $-15^{\circ} /+15^{\circ}$

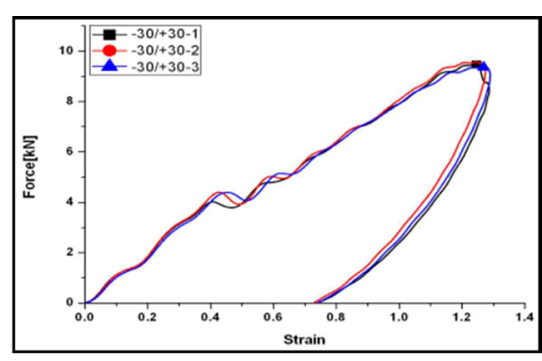

(c) $-30^{\circ} /+30^{\circ}$

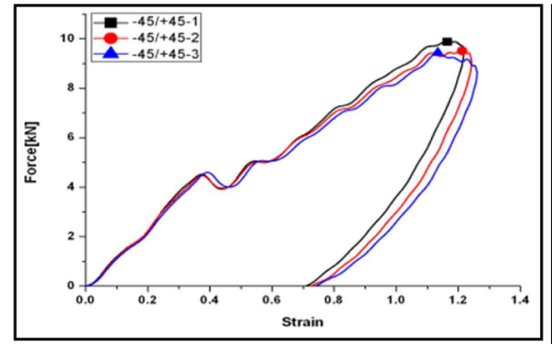

(d) $-45^{\circ} / 45^{\circ}$

Fig. 3. Load-strain curves for samples with symmetric laminated angles.

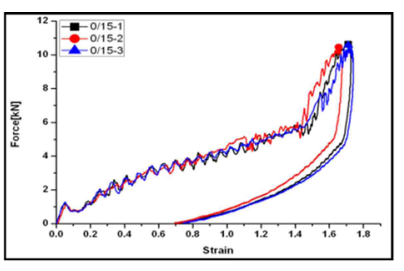

(a) $0^{\circ} 15^{\circ}$

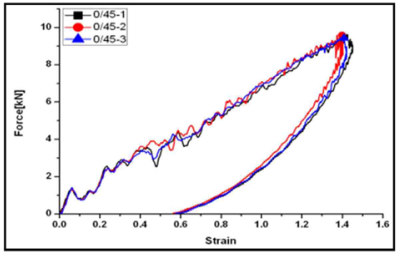

(c) $0^{\circ} / 45^{\circ}$

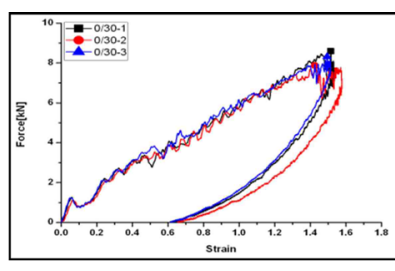

(b) $0^{\circ} / 30^{\circ}$

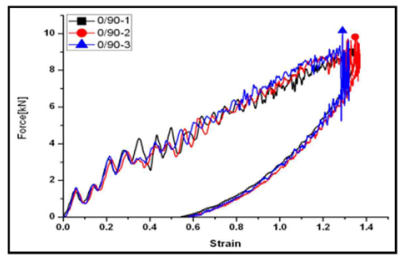

(d) $0 \% 90^{\circ}$
Fig. 4. Load-strain curves for samples with asymmetric laminated angles.

drop-weight tests for specimens manufactured with symmetric ply, namely $0^{\circ} / 0^{\circ},-15^{\circ} / 15^{\circ},-30^{\circ} /+30^{\circ},-45^{\circ} /+45^{\circ}$, and $-90^{\circ} /+90^{\circ}$, respectively. The average load, strain, and average adsorbed energy calculated from three specimens each for each of the laminated orientations were $6.20 \mathrm{kN}, 2.2649 \mathrm{~mm} /$ $\mathrm{mm}$, and $22.60 \mathrm{~J} ; 8.1668 \mathrm{kN}, 1.4596 \mathrm{~mm} / \mathrm{mm}$, and $27.7841 \mathrm{~J}$; $9.4798 \mathrm{kN}, 1.2835 \mathrm{~mm} / \mathrm{mm}$, and $27.9702 \mathrm{~J} ; 9.6157 \mathrm{kN}, 1.23$ $\mathrm{mm} / \mathrm{mm}$, and $27.7351 \mathrm{~J}$; and $8.9850 \mathrm{kN}, 2.1522 \mathrm{~mm} / \mathrm{mm}$, and $27.0334 \mathrm{~J}$, respectively. Fig. 4 shows the load-strain graph at various laminated angles for the asymmetric specimens. Fig. 4 show the results of the drop-weight tests with CFRP samples having laminated angles of $0^{\circ} / 15^{\circ}, 0^{\circ} / 30^{\circ}, 0^{\circ} / 45^{\circ}$, and $0^{\circ} / 90^{\circ}$, respectively. The average load, strain, and average adsorbed energy calculated from three specimens each for

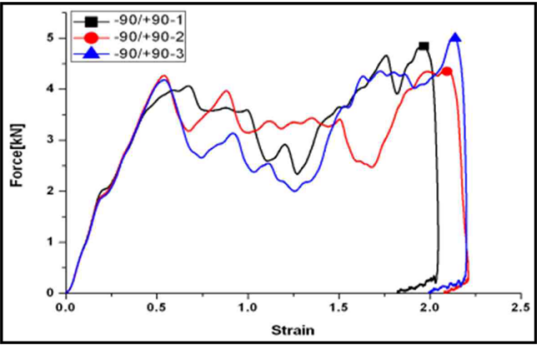

(e) $-90^{\circ} /+90^{\circ}$ each of the laminated angles were $10.58 \mathrm{kN}, 1.171331 \mathrm{~mm} /$ $\mathrm{mm}$, and $30.76 \mathrm{~J} ; 8.2 \mathrm{kN}, 1.541249 \mathrm{~mm} / \mathrm{mm}$, and $30.72 \mathrm{~J} ; 9.5$ $\mathrm{kN}, 1.42546 \mathrm{~mm} / \mathrm{mm}$, and $30.63 \mathrm{~J}$; and $9.68 \mathrm{kN}, 1.346359$ $\mathrm{mm} / \mathrm{mm}$, and $30.67 \mathrm{~J}$, respectively $[3,4]$.

Table 3 lists the average results of the drop-weight impact tests. The specimen at $0^{\circ} / 15^{\circ}$ has the biggest load in the dropweight impact test, whereas the specimen at $0^{\circ} / 0^{\circ}$ exhibits the biggest strain. In the cases of the symmetric specimens, the greater the increase in the fiber angle, the greater is the decrease in strain, except for the $0^{\circ} / 0^{\circ}$ and $-90^{\circ} /+90^{\circ}$ samples. The same is true in the cases of the asymmetric specimens. The specimens with $0^{\circ} / 0^{\circ}$ and $-90^{\circ} /+90^{\circ}$ show the largest, because the fiber and matrix cause delamination in the dropweight impact tests.

Fig. 5 shows the relationship between the absorbed energy and maximum strain as a function of the laminated angle [5]. Fig. 5a presents a plot of the absorbed energy observed during the impact tests. The absorbed energies in the asymmetric cases are larger than the adsorbed energies in the symmetric cases. Fig. 5b shows a plot of the maximum strain observed during the impact tests. In general, the greater the increase in the fiber angle, the greater is the decrease in strain. However, as an exception, the $-90^{\circ} /+90^{\circ}$ sample exhibited high strain. Fig. 6 shows images of fractured specimens at various laminated symmetry angles during the drop-weight impact tests. CD is the direction of the crack, and FD is the direction of the fibers. Fig. 7 shows images of fractured specimens at various laminated asymmetry angles from the drop-weight impact tests. As shown in Figs 6 and 7, CD is perpendicular to FD. Thus, the direction of the crack is perpendicular to the fiber direction.

To examine the temperature distribution during the dropweight tests for the CFRP at each fiber-laminated angle, the 
Table 3. Results of the drop-weight impact tests

\begin{tabular}{ccccc} 
Specimen & Impact energy $(\mathrm{J})$ & Absorbed energy $(\mathrm{J})$ & Max load $(\mathrm{kN})$ & Max strain $(\mathrm{mm} / \mathrm{mm})$ \\
\hline $0^{\circ} / 0^{\circ}$ & 30.78 & 22.60 & 6.20 & 2.27 \\
$-15^{\circ} /+15^{\circ}$ & 30.58 & 27.78 & 8.17 & 1.46 \\
$-30^{\circ} /+30^{\circ}$ & 30.46 & 27.97 & 9.48 & 1.29 \\
$-45^{\circ} / 45^{\circ}$ & 30.53 & 27.74 & 9.62 & 1.23 \\
$-90^{\circ} / 90^{\circ}$ & 30.62 & 27.03 & 8.99 & 2.15 \\
$0^{\circ} / 15^{\circ}$ & 30.76 & 28.46 & 10.58 & 1.71 \\
$0^{\circ} / 30^{\circ}$ & 30.72 & 29.11 & 8.20 & 1.54 \\
$0^{\circ} / 45^{\circ}$ & 30.63 & 29.83 & 9.50 & 9.68 \\
$0^{\circ} / 90^{\circ}$ & 30.67 & 29.10 & & 1.43 \\
\hline
\end{tabular}

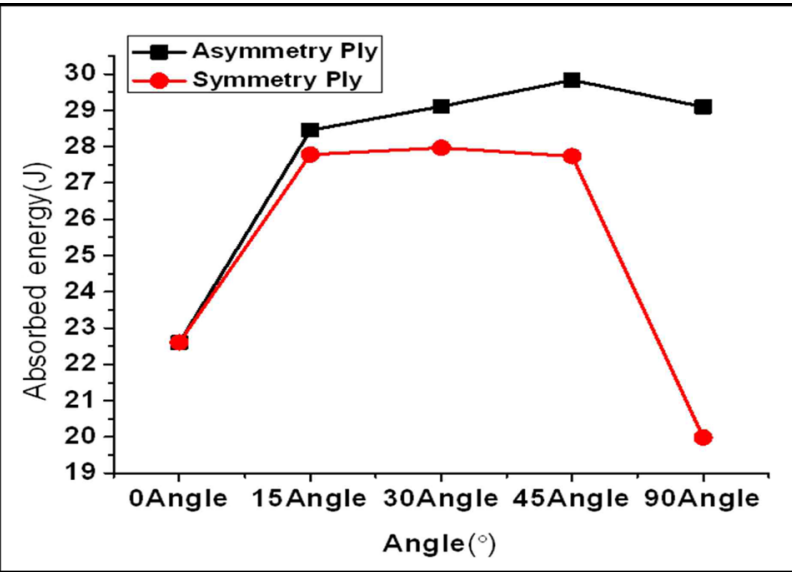

(a)

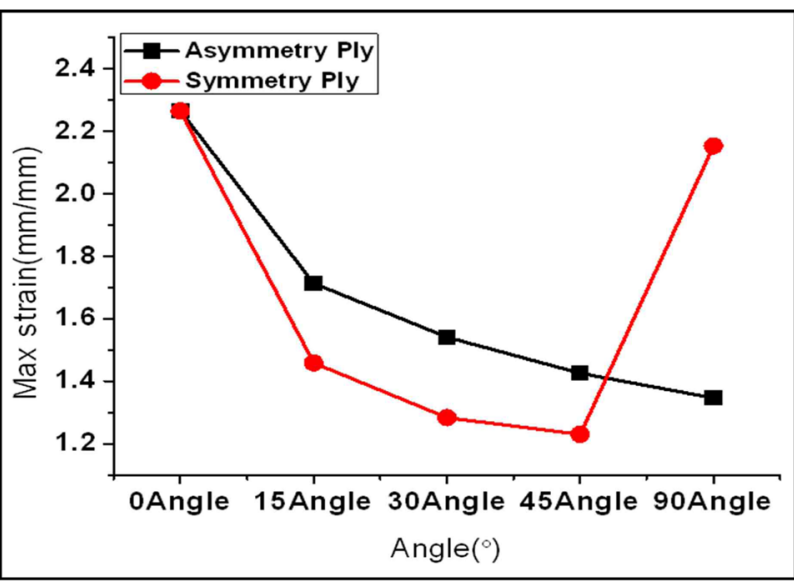

(b)

Fig. 5. Relationship between absorbed energy and the maximum strain as a function of laminated angle. Plots of (a) absorbed energy and (b) maximum strain observed during the impact test, as a function of laminated angle. temperature distribution was measured using an infrared thermograph camera, until the material was fractured. Figs 8 and 9 show the infrared thermograph image of the fractured specimens and the measured maximum temperature and average temperature of the fractured specimen area, respectively. Fig. 8 [5] shows the temperature distribution during the dropweight tests for the CFRP samples with symmetric laminated angles.

Fig. 8a shows the temperature distribution during the CFRP drop-weight impact test with the $0 \% 0^{\circ}$ laminated angle. The max temperature on the fractured surface was $102.96^{\circ} \mathrm{C}$, which was approximately $78.68^{\circ} \mathrm{C}$ higher than before the fracture. Fig. $8 \mathrm{~b}$ shows the temperature distribution during the CFRP drop-weight impact test with the $-15^{\circ} /+15^{\circ}$ laminated angle. The max temperature on the fractured surface was $29.26^{\circ} \mathrm{C}$, which was approximately $5.67^{\circ} \mathrm{C}$ higher than before the fracture. Fig. $8 \mathrm{c}$ shows the temperature distribution during the CFRP drop-weight impact test with the $-30^{\circ} \%+30^{\circ}$ laminated angle. Fig. 9 shows the temperature distribution during the drop-weight tests for the CFRP samples with asymmetric laminated angles. Fig. 9 show the temperature distributions during the CFRP drop-weight impact tests for specimens with laminated angles of $0^{\circ} / 15^{\circ}, 0^{\circ} / 30^{\circ}$, $0^{\circ} / 45^{\circ}$, and $0^{\circ} / 90^{\circ}$, respectively. The maximum temperatures on the fractured surfaces of these specimens were $58.51^{\circ} \mathrm{C}$, $32.6^{\circ} \mathrm{C}, 36.92^{\circ} \mathrm{C}$, and $36.17^{\circ} \mathrm{C}$, respectively, which were approximately $34.12^{\circ} \mathrm{C}, 8.07^{\circ} \mathrm{C}, 12.4^{\circ} \mathrm{C}$, and $11.61^{\circ} \mathrm{C}$ higher than the temperatures before fracture, respectively. Fig. 10 shows the relationship between the maximum temperature gap and absorbed energy of the drop-weight impact tests measured with an infrared camera as a function of the fiberlaminated angle.

The maximum temperature gaps measured during the dropweight impact tests with an infrared camera are greater for the laminated samples with symmetric angles than those for the laminated samples with asymmetric angles. Although all the specimens received nearly the same impact energy, the maximum temperature gap is inversely related to the absorbed energy when the specimen received the impact energy. 


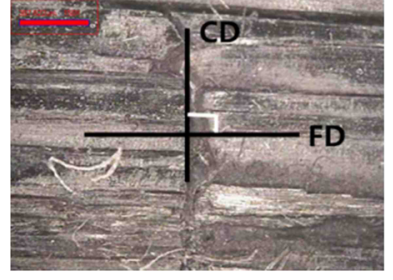

(a) $0 \% 0^{\circ}$

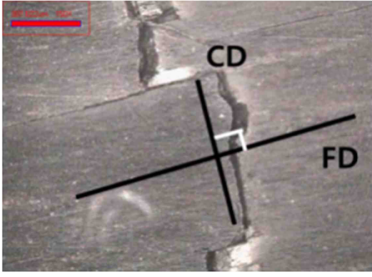

(b) $-15^{\circ} / 15^{\circ}$

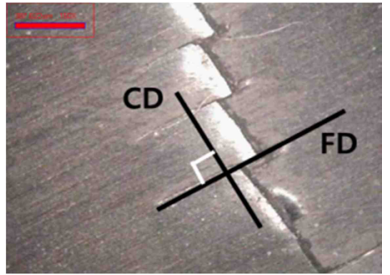

(c) $-30^{\circ} / 30^{\circ}$

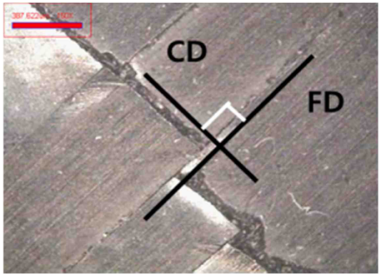

(d) $-45^{\circ} / 45^{\circ}$

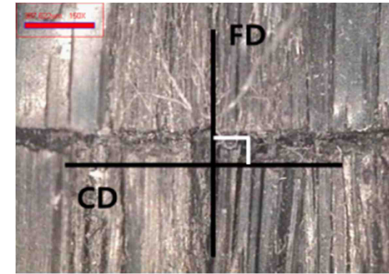

(e) $-90^{\circ}+90^{\circ}$

Fig. 6. Images of fractured specimens with symmetric laminated angles from the drop-weight impact tests. CD: Crack direction, FD: Fiber direction.

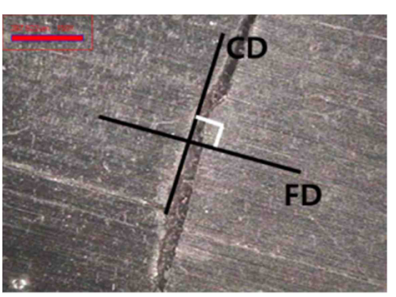

(a) $0^{\circ} / 15^{\circ}$

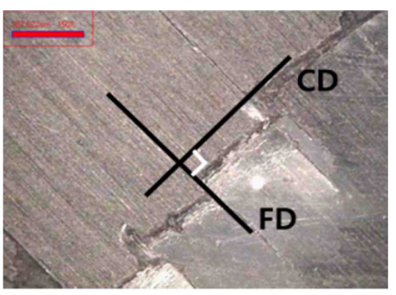

(c) $0^{\circ} / 45^{\circ}$

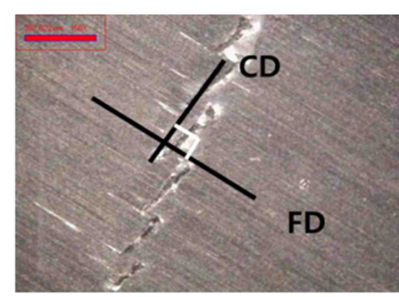

(b) $0^{\circ} / 30^{\circ}$

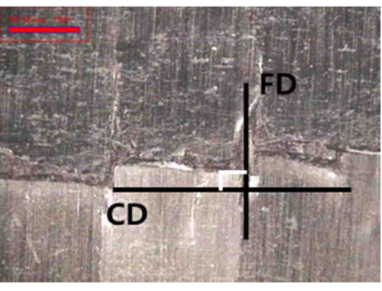

(d) $0^{\circ} / 90^{\circ}$
Fig. 7. Images of fractured specimens with asymmetric laminated angles from the drop-weight impact tests. CD: Crack direction, FD: Fiber direction.

\section{Conclusions}

In this study, correlations between the mechanical and thermal characteristics of CFRPs were determined using dropweight impact tests at various fiber-laminated angles. The following results were obtained.

1) In the drop-weight impact test, the $0^{\circ} / 15^{\circ}$ specimen had the biggest load, whereas the $0^{\circ} / 0^{\circ}$ specimen exhibited the biggest strain. For the symmetric specimens, the greater the increase in the fiber angle, the greater was the decrease in strain, except for the $0^{\circ} / 0^{\circ}$ and $-90^{\circ} /+90^{\circ}$ specimens. The same was true for the asymmetric samples. The $0^{\circ} / 0^{\circ}$ and $-90^{\circ} /+90^{\circ}$ specimens were the largest, because the fiber and matrix caused delamination during the drop-weight impact tests. The absorbed energy of the asymmetric samples was bigger than that for the symmetric samples. In terms of strain, the greater the increase in the fiber angle, the greater was the decrease in strain, except for the $-90^{\circ} /+90^{\circ}$ specimen, because the laminated angle of this specimen was similar to

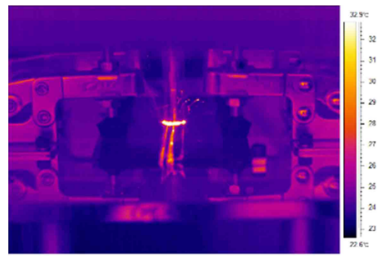

(a) $0^{\circ} / 0^{\circ}$

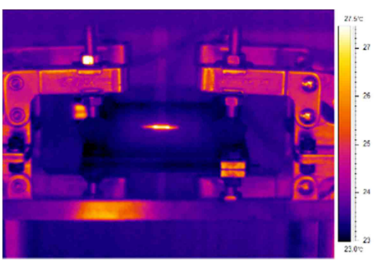

(b) $-15^{\circ} /+15^{\circ}$

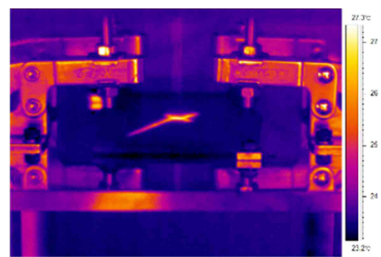

(c) $-30 \%+30^{\circ}$

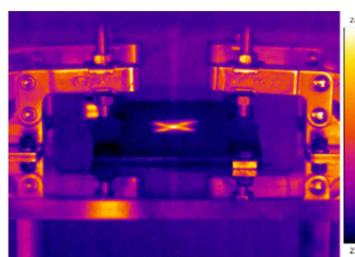

(d) $-45^{\circ} / 45^{\circ}$

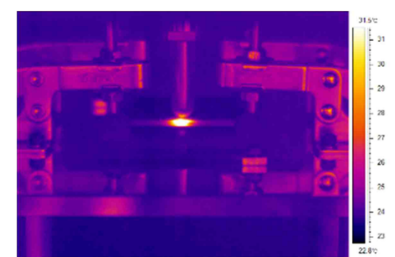

(e) $-90^{\circ} / 90^{\circ}$

Fig. 8. Infrared thermograph images of specimens with symmetric laminated angles from the drop-weight impact tests. 


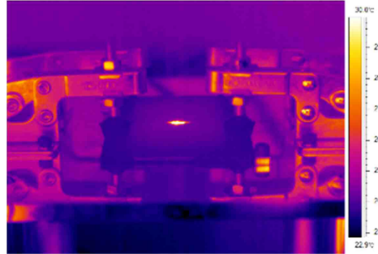

(a) $0^{\circ} / 15^{\circ}$

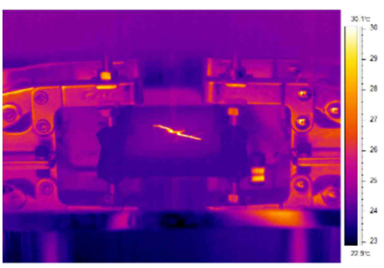

(c) $0^{\circ} / 45^{\circ}$

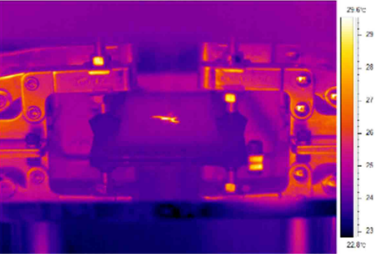

(b) $0^{\circ} / 30^{\circ}$

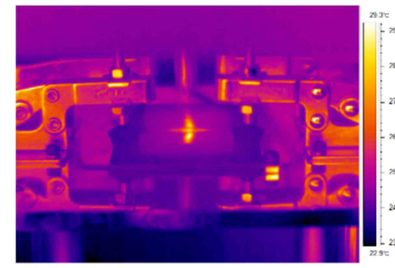

(d) $0^{\circ} / 90^{\circ}$
Fig. 9. Infrared thermograph images of specimens with asymmetric laminated angles from the drop-weight impact tests.

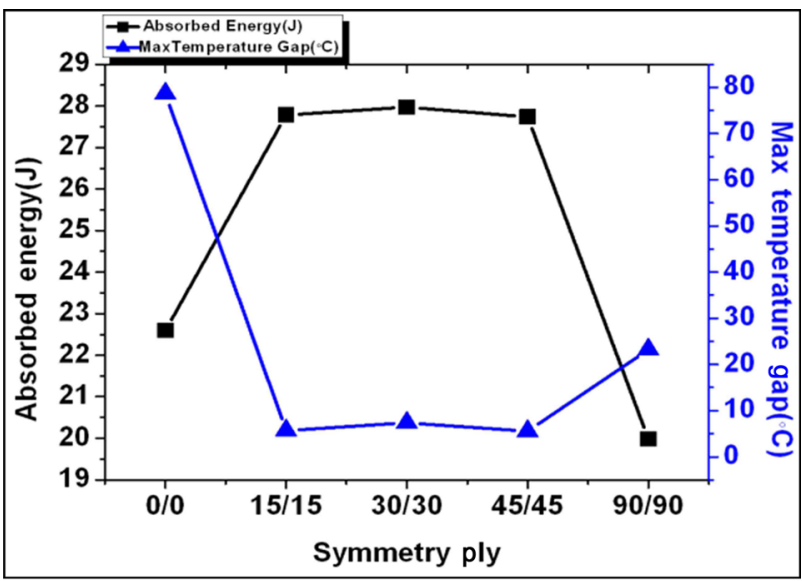

(a)

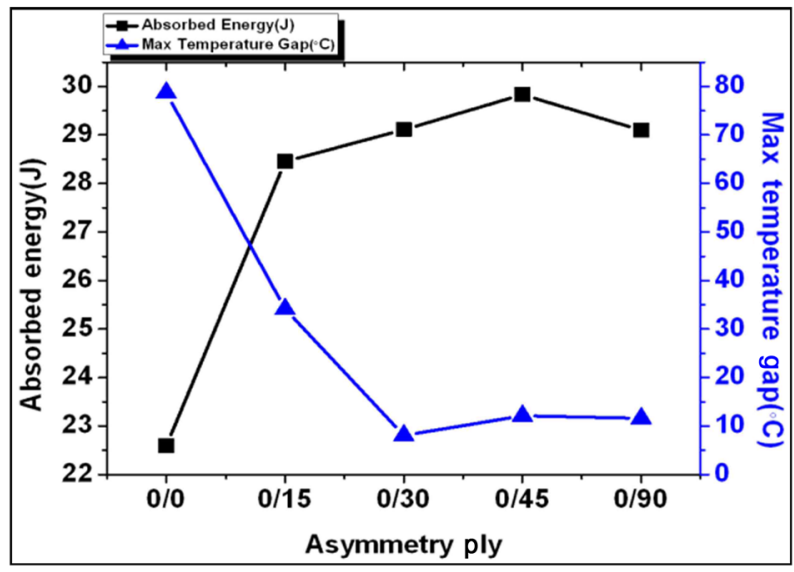

(b)

Fig. 10. Correlation between the maximum temperature gap and absorbed energy for specimens with (a) symmetric and (b) asymmetric laminated angles. the angle of the $0^{\circ} / 0^{\circ}$ specimen. Thus, the more the specimen absorbed energy, the more it emits high heat.

2) Infrared camera measurements of the CFRP specimens revealed that the maximum temperature gap was largest for the $0^{\circ} / 0^{\circ}$ specimen, and the maximum temperature gaps measured during the drop-weight impact tests as a function of the laminated angle for the symmetric samples were higher than those for the asymmetric specimens. Although all the specimens experienced nearly the same impact energy, the maximum temperature gap was inversely related to the absorbed energy when the specimen received the impact energy, because the temperature gap in the drop-weight impact tests is also a form of energy.

\section{Acknowledgments}

This research was supported by the National Foundation of Korea (NRF) grant funded by the Korea Government (MISP) (No. 2014R1A2A1A11053533) and supported by the basic science research program through the National Research Foundation of Korea (NRF) funded by the Ministry of Education, Science and Technology (No. 2013R1A1A2061581) and financially supported by the Ministry of Education, Science Technology (MEST) and National Research Foundation of Korea (NRF) through the Human Resource Training Project for Regional Innovation (No.2012H1B8A2026147).

\section{References}

[1] Jun JK, Kwon OY, Lee U. Damage assessment of curved composite laminate structures subjected to low-velocity impact. Korean Soc Compos Mater, 14, 22 (2001).

[2] Camponeschi ET Jr. Compression of Composite Materials: A Review. In: O’Brien TK, ed. Composite Materials: Fatigue and Fracture, Vol. 3, ASTM, Philadelphia, 550 (1991).

[3] Shin HJ, Kwac LK, Ko SH, Kim TH, Kim HG. A study on impact strength of CFRP using infrared thermography. Adv Mater Res, 628, 390 (2013). http://dx.doi.org/10.4028/www.scientific.net/ AMR.628.390.

[4] Shin HJ. The Strength Evaluation and Nondestructive Testing of Carbon Fiber Composites, Jeonju University, Jeonju, MS Thesis (2013).

[5] Kim TH. Analysis of Correlation according to the Orientation of Carbon Fiber Composite Mechanical and Thermal Properties, Jeonju University, Jeonju, MS Thesis (2012).

[6] American Society for Testing Materials D7136/D7136M. ASTM D7136/D7136M-15, Standard Test Method for Measuring the Damage Resistance of a Fiber-Reinforced Polymer Matrix Composite to a Drop-Weight Impact Event, ASTM International, West Conshohocken, PA, 2015. http://dx.doi.org/10.1520/D7136_ D7136M-15.

[7] Stanley P. Applications and potential of thermoelastic stress analysis. J Mater Process Technol, 64, 359 (1997). http://dx.doi org/10.1016/S0924-0136(96)02587-3. 